\title{
Duplicação da veia cava inferior
}

\section{Duplication of the inferior vena cava}

Apresenta-se o caso de um doente do sexo masculino, com 83 anos de idade, que no decurso de investigação de quadro de suboclusão intestinal realizou uma tomografia axial computadorizada (TAC) (Fig. 1 y 2), que revelou a presença de duas veias cavas inferiores (setas brancas), unindo-se imediatamente na porção pré-hepática (variante do normal). Pode observar-se a artéria aorta, com calcificações, entre ambas as veias cavas inferiores.

0 desenvolvimento da veia cava ocorre entre a $6^{\mathrm{a}}$ e $10^{\mathrm{a}}$ semanas de gestação, a partir da veia supracardinal direita, enquanto que a veia supracardinal esquerda involui. A sua duplicação ocorre como resultado da persistência de ambas as veias supracardinais (direita e esquerda) e tem uma prevalência estimada de 0.2-0.3\%.

Geralmente, é uma anomalia assintomática, detectada acidentalmente em exames imagiológicos. Contudo, o seu diagnóstico é importante, uma vez que a sua presença tem implicações clínicas relevantes, nomeadamente no tratamento de doenças tromboembólicas.

\section{Diagnóstico:}

Duplicação da Veia Cava Inferior

João Faria', Rui Moço ${ }^{1}$

${ }^{1}$ Serviço de Medicina Interna. Hospital Pedro Hispano. Matosinhos. Portugal

Como citar este artículo: Faria J, Moço $R$

Duplicação da Veia Cava Inferior. Galicia Clin 2012; 73 (3): 133

Recibido 24/06/2012; Aceptado 26/06/2012
Figura 1 y 2
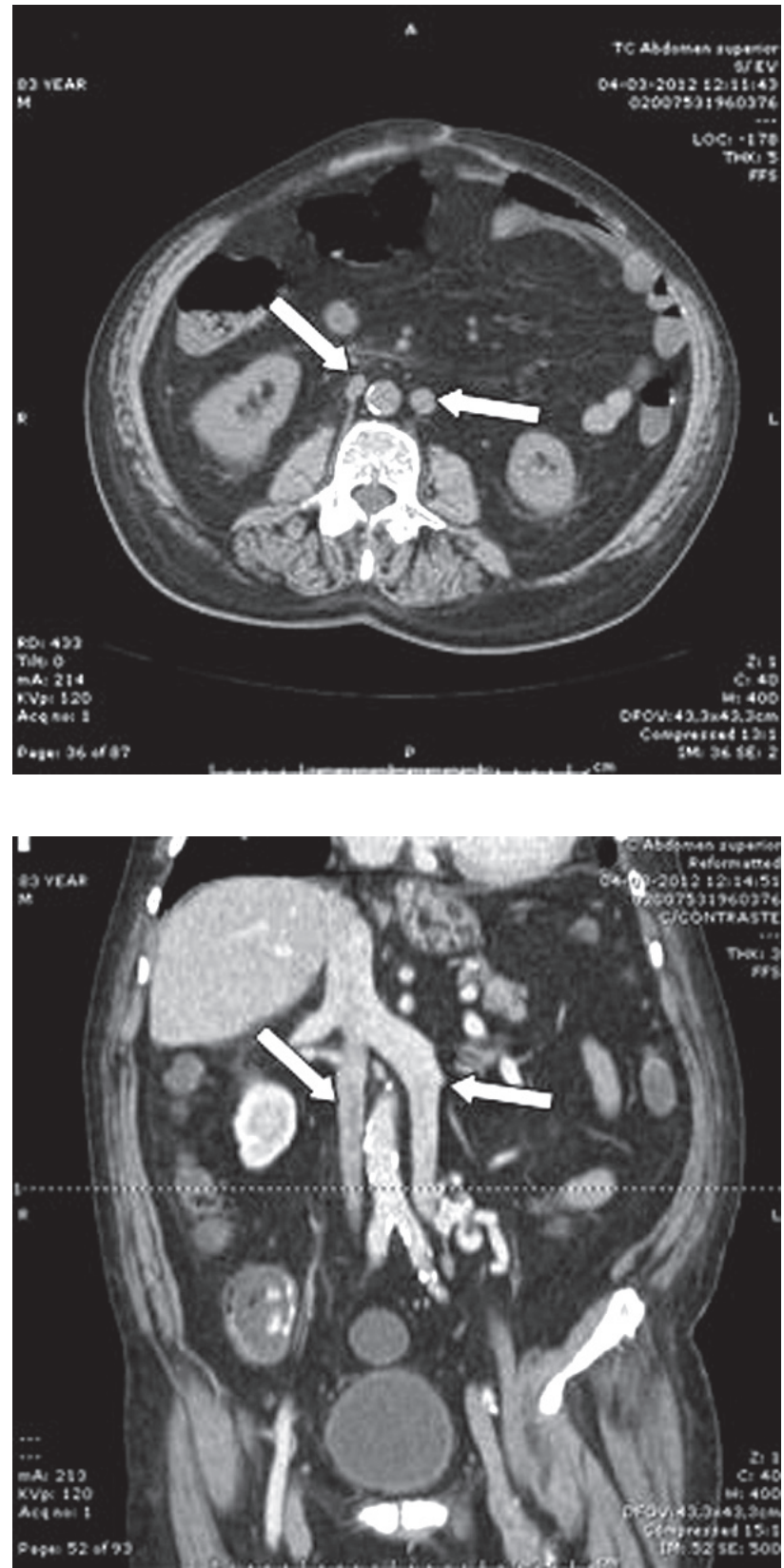